\title{
Some Neutron and Gamma Radiation Characteristics of Plutonium Cermet Fuel for Isotopic Power Sources
}

\author{
R. A. NEFF, M. E. ANDERSON, A. R. CAMPBELL, and F. X. HAAS \\ Mound Labbratory, Miamisburg. Ohio*
}

\begin{abstract}
Gamma and neutron measurements on various types of plutonium sources are presented in order to show the effects of ${ }^{17} 0,{ }^{18} 0$, ${ }^{19} \mathrm{~F},{ }^{3 в} \mathrm{Pu}$, age of the fuel, and size of the source on the gamma and neutron spectra. Analysis of the radiation measurements shows that fluorine is the main contributor to the neutron yields from present plutonium-molybdenum cermet fuel while both fluorine and ${ }^{2{ }^{6}} \mathrm{Pu}$ daughters contribute significantly to the gamma-ray intensities.
\end{abstract}

Plutonium-238 has many desirable qualities for a radioisotopic heat source fuel and has been used in numerous heat sources for terrestrial, marine and space applications: The plutonium fuel has been prepared in several different forms depending on the requirements of the particular mission and the technology available at the time of fabrication. Fuel forms used in the past have been plutonium metal, alloys, and dioxide microspheres. The most recent fuel form to be used is plutonium-molybdenum cermet, (PMC), which is plutonium dioxide that has been coated with molybdenum and hot pressed into the desired shape. This paper deals with the gamma and neutron radiation emitted by the PMC fuel.

The gamma radiation can be divided into three groups; that due to radioactive decay of ${ }^{238} \mathrm{Pu}$ and other nuclides, alpha particle reactions, and fission of the plutonium. Figure 1 shows the gamma spectrum obtained with a Ge(Li) spectrometer of a 15watt Apollo heat source fueled with plutonium dioxide microspheres. In this spectrum we can see the ${ }^{238} \mathrm{Pu}$ full energy peaks at 100,153 , and $208 \mathrm{keV}$, severa 1 peaks centered around the intense $766 \mathrm{keV}$ peak, and peaks at $851,883,926,942$, and $1001 \mathrm{keV}$. There are some other less intense ${ }^{238} \mathrm{Pu}$ peaks which do not show up in this spectrum.
The fuel used in heat sources is nomina11y about $80 \%{ }^{238} \mathrm{Pu}, 16 \%{ }^{239} \mathrm{Pu}$, and 1.2 ppm ${ }^{236} \mathrm{Pu}$. The ${ }^{339} \mathrm{Pu}$ contributes a group of peaks around $400 \mathrm{keV}$ while the main contributions from ${ }^{238} \mathrm{Pu}$ are the two intense peaks at 2614 and $583 \mathrm{keV}$ due to the ${ }^{38} \mathrm{Tl}$ daughter. Other peaks from ${ }^{238} \mathrm{Pu}$ daughters which can be seen in this spectrum are the 510 and $860 \mathrm{keV}$ peaks also from ${ }^{208} \mathrm{Tl}$, the 240 and $301 \mathrm{keV}$ peaks from ${ }^{21 a} \mathrm{~Pb}$, and the 727 and $1620 \mathrm{keV}$ peaks from $213 \mathrm{Bi}$. However, a portion of the $510 \mathrm{keV}$ peak is due to annihilation radiation following pair production from the more energetic gamma rays. About five years after chemical separation, the gamma dose rate from the ingrowth of these ${ }^{238} \mathrm{Pu}$ daughters is about equal to the dose rate from the ${ }^{2}{ }^{3} \mathrm{Pu}$ gammas for a small encapsulated heat source. The dose rate from these daughters reaches a maximum at 18 years after separation at which time it is $\sim 2.5$ times the dose rate from the ${ }^{238} \mathrm{Pu}$ gammas.

Another source of gamma rays is fission, both spontaneous and neutron induced, which will give approximately an exponential continuum of gamma rays. For the Pioneer Program, there was some concern over the gamma rays in the 1 to $4 \mathrm{MeV}$ range. We estimate that for a source the size of the Pioneer there are about 1.8 $\times 10^{4}$ photons/sec/watt in the $1-2 \mathrm{MeV}$

*Operated by Monsanto Research Corporation for the United States Atomic Energy Commission under Contract No. AT-33-1-GEN-53. 


\section{DISCLAIMER}

This report was prepared as an account of work sponsored by an agency of the United States Government. Neither the United States Government nor any agency Thereof, nor any of their employees, makes any warranty, express or implied, or assumes any legal liability or responsibility for the accuracy, completeness, or usefulness of any information, apparatus, product, or process disclosed, or represents that its use would not infringe privately owned rights. Reference herein to any specific commercial product, process, or service by trade name, trademark, manufacturer, or otherwise does not necessarily constitute or imply its endorsement, recommendation, or favoring by the United States Government or any agency thereof. The views and opinions of authors expressed herein do not necessarily state or reflect those of the United States Government or any agency thereof. 


\section{DISCLAIMER}

Portions of this document may be illegible in electronic image products. Images are produced from the best available original document. 
Figure 1

HEAT SOURCE OXIDE FUEL FORM
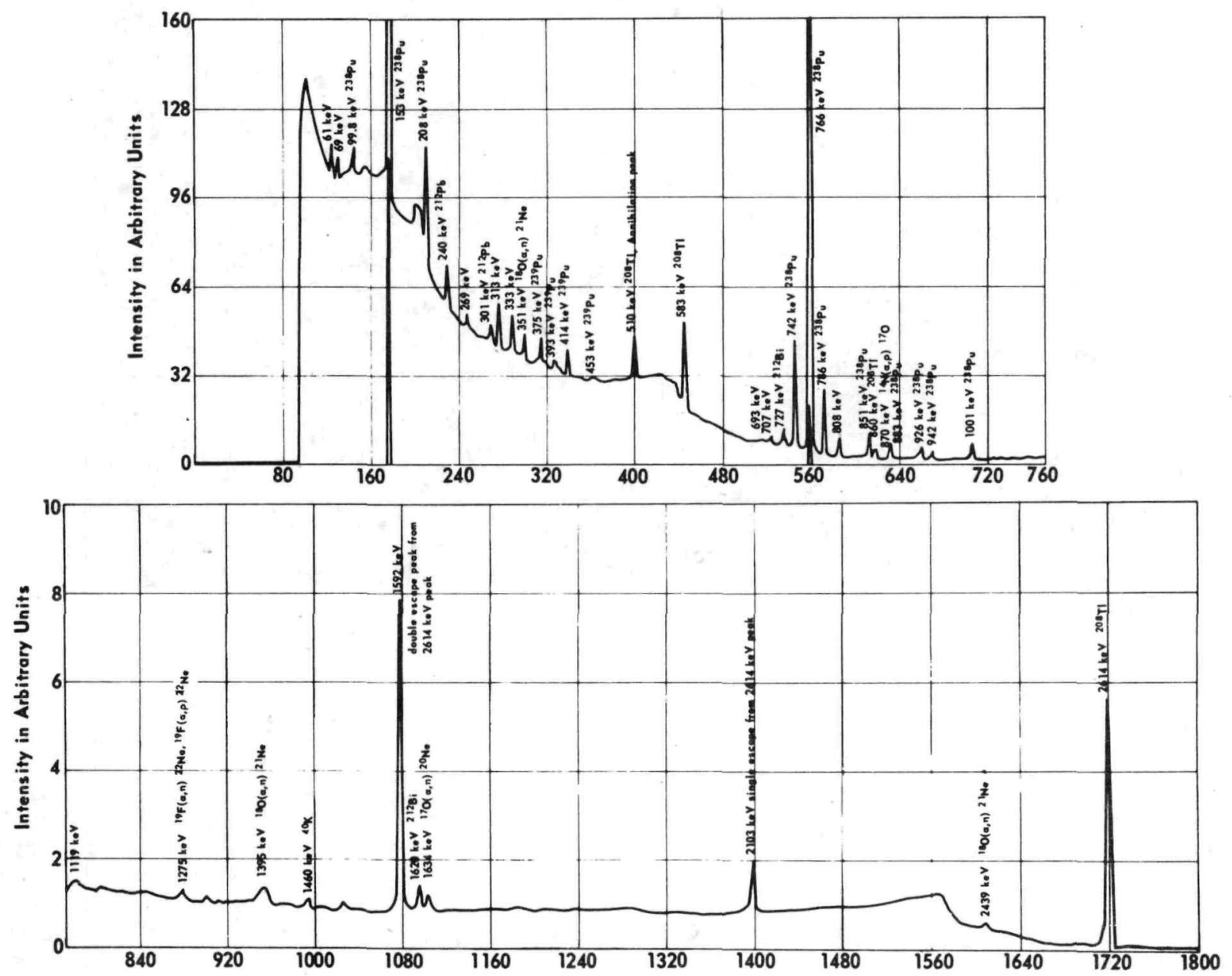

range due to fission, $6.0 \times 10^{3}$ in the $2-3 \mathrm{MeV}$ range, and $1.9 \times 10^{3}$ in the $3-4$ $\mathrm{MeV}$ range. These estimates are for bare fuel and have not been corrected for selfabsorption within the source. To compare these intensities to the ${ }^{238} \mathrm{Pu}$ photopeaks, the 742,766 , and $786 \mathrm{keV}$ peaks give a total of $\sim 5.1 \times 10^{5}$ photons/sec/watt from a bare source with no self-absorption, and the total of other ${ }^{338} \mathrm{Pu}$ gamma rays between 880 and 1085 is $2.4 \times 10^{4}$ photons/ $\mathrm{sec} / \mathrm{watt}$.
Figure 2 shows the gamma spectra of three different plutonium sources obtained with a $\mathrm{Ge}(\mathrm{L} i)$ spectrometer. The top spectrum in this figure is of a metal source containing about seven grams of ${ }_{38} \mathrm{Pu}$. This spectrum shows the prominent a ${ }^{8} \mathrm{Pu}$ peaks (some of which are labeled by energy) as well as the peaks due to ${ }^{338} \mathrm{Pu}$ daughters. Since this source is about seven years old, these peaks from ${ }^{236} \mathrm{Pu}$ daughters are relatively intense. 
Figure 2

GAMMA SPECTRA OF $\mathrm{Pu}, \mathrm{PuF}_{4}$, and $\mathrm{PuO}_{2}$

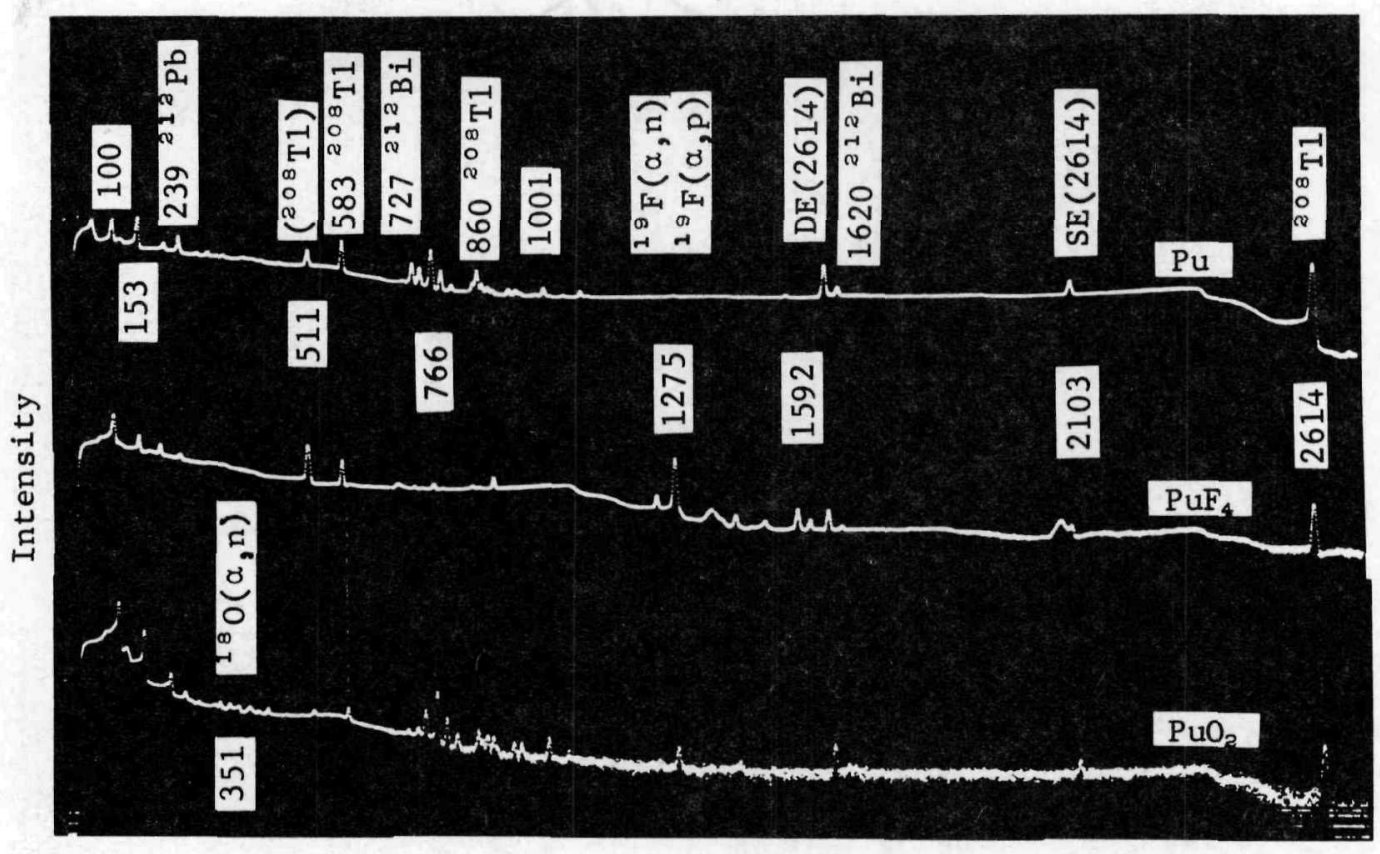

Gamma Energy (keV)

The bottom curve in Figure 2 shows the gamma spectrum of a $\mathrm{PuO}_{2}$ source containing about 1.5 grams of ${ }^{238} \mathrm{Pu}$. Comparing the top and bottom curves, we can see that the presence of oxygen gives only a few relatively weak gamma rays. These are at 351,1395 , and $2439 \mathrm{keV}$ from ${ }^{18} \mathrm{o}(\alpha, \mathrm{n} \gamma)$ reactions and at $1634 \mathrm{keV}$ from the ${ }^{17} 0$ $(\alpha, n \gamma)$ reaction. For this oxide source, the gamma rays from the ${ }^{236} \mathrm{Pu}$ daughters are not as intense relative to the ${ }^{238} \mathrm{Pu}$ gamma rays since the material is much younger than the metal source. However, the ${ }^{208} \mathrm{~T} 1$ peaks at 583 and $2614 \mathrm{keV}$ are sti11 prominent.

The gamma spectrum of a $\mathrm{PuF}_{4}$ source containing about 0.5 grams of ${ }^{238} \mathrm{Pu}$ is shown as the middle curve in Figure 2 . The contribution to the gamma spectrum due to fluorine can be seen as a very intense peak at $1275 \mathrm{keV}$ due to both $(\alpha, \mathrm{p})$ reactions on ${ }^{19} \mathrm{~F}$ and the decay of ${ }^{2 a} \mathrm{Na}$ formed by the ${ }^{19} \mathrm{~F}(\alpha, \mathrm{n})^{2 \mathrm{a}} \mathrm{Na}$ reaction. There are other peaks due to fluorine at 580,890 , and $2080 \mathrm{keV}$ and five additional peaks clustered around the $1275 \mathrm{keV}$ peak. In normal heat source material, the fluorine content is low enough that the only significant contribution from the fluorine reactions is the peak at $1275 \mathrm{keV}$.
Since a portion of the $1275 \mathrm{keV}$ peak is due to the decay of ${ }^{2 a} \mathrm{Na}$ formed by ${ }^{19} \mathrm{~F}$ $(\alpha, n)^{2 a} \mathrm{Na}$ reactions, the intensity of this peak will increase with time up to about six years (two half-1ives of ${ }^{a} \mathrm{Na}$ ) after the introduction of fluorine. After six years, secular equilibrium is reached and the intensity of the $1275 \mathrm{keV}$ peak remains constant relative to the ${ }^{238} \mathrm{Pu}$ gamma rays. Measurements have shown that the intensity of the $1275 \mathrm{keV}$ peak will approximately double over this six year period.

Since the $\mathrm{PuF}_{4}$ source used for Figure 2 was over six years old, the spectrum readily shows the gamma rays from the ${ }^{36} \mathrm{Pu}$ daughters as well as some of the more prominent ${ }^{238} \mathrm{Pu}$ peaks.

Shown in Figure 3 is the gamma-ray spectrum of a 647-watt Pioneer capsule fueled with plutonium-molybdenum cermet. Notice the absence of structure below. about $500 \mathrm{keV}$ as compared to the spectra shown in Figures 1 and 2 . This is due mostly to the greatly increased self-absorption for this source. We still see the ${ }^{238} \mathrm{Pu}$ group around $766 \mathrm{keV}$ and the $1001 \mathrm{keV}$ peak, also the ${ }^{308} \mathrm{~T} 1$ peaks at 583 and $2614 \mathrm{keV}$, and the fluorine peak at $1275 \mathrm{keV}$. The peak at $2223 \mathrm{keV}$ is 
GAMMA SPECTRUM OF PF-2
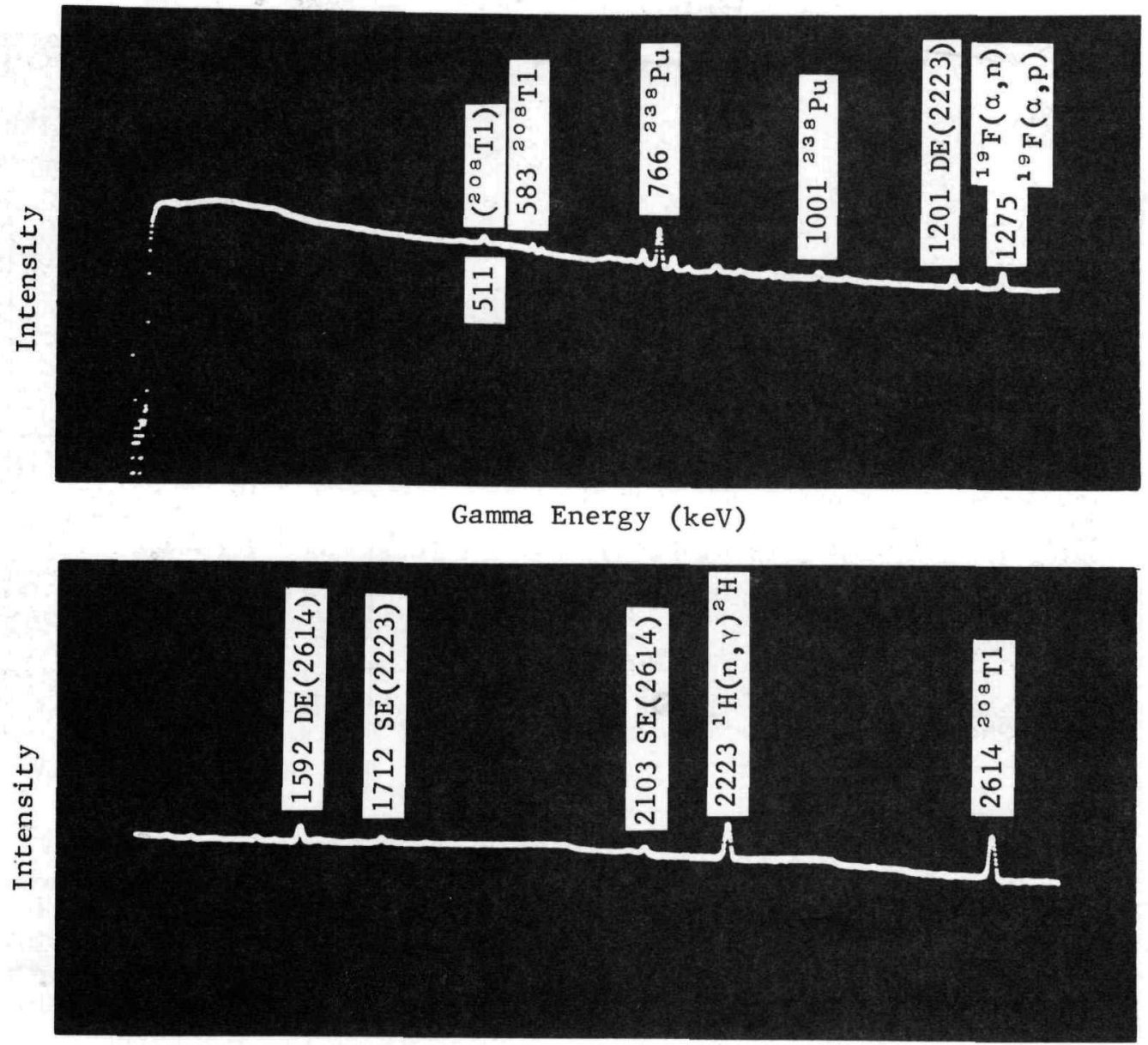

Gamma Energy (keV)

not from the source but was caused by the ${ }^{1} \mathrm{H}(\mathrm{n}, \mathrm{\gamma})^{2} \mathrm{H}$ reaction with the water bath the source was in during the measurements.

The neutrons from PMC fuel are contributed by spontaneous fission of ${ }^{238} \mathrm{Pu}$, neutron induced fission of the $\mathrm{Pu}$, and $(\alpha, n)$ reactions primarily with ${ }^{17} 0,{ }^{18} 0$, and ${ }^{19} \mathrm{~F}$. Figure 4 shows the neutron spectrum of a 15-watt plutonium metal source. About $75 \%$ of the neutrons from this source are from spontaneous fission of the ${ }^{338} \mathrm{Pu}$ while the remaining $25 \%$ are mostly due to $(\alpha, n)$ reactions with low $\mathrm{Z}$ impurities. Since the neutrons above $\sim 5 \mathrm{MeV}$ are almost all due to spontaneous fission, this portion of the spectrum was fitted to a Maxwe 11ian distribution in order to approximate a fission spectrum. The spontaneous fission neutron yield is about $2.65 \times 10^{3} \mathrm{n} / \mathrm{sec} /$ gram of ${ }^{3}{ }^{8} \mathrm{Pu}$.
This value is represented by the lower curve in this figure and is the minimum number of neutrons that $a^{23} 8 \mathrm{Pu}$ source

can emit. The average neutron energy for this fission curve is $2.0 \mathrm{MeV}$.

Even though PMC fuel is enriched in ${ }^{16} 0$ which will not undergo $(\alpha, n)$ reactions with the $5.5 \mathrm{MeV}{ }^{238} \mathrm{Pu}$ alpha particles, there are still sufficient quantities of ${ }^{17} 0$ and ${ }^{18} 0$ present to produce significant quantities of neutrons. The effects of ${ }^{17} 0$ and ${ }^{18} 0$ on the neutron spectrum are shown in Figure 5 . This is the spectrum of a $\mathrm{PuO}_{2}$ source in which the oxygen is enriched to $45.6 \%^{18} 0$ and $1.7 \%^{17} 0$ whereas natura 1 oxygen is $0.2 \%^{18} 0$ and $0.04 \%^{17} 0$. The data at energies greater than $1 \mathrm{MeV}$ were obtained with a stilbene spectrometer while the datum point between 0 and $1 \mathrm{MeV}$ was obtained from a difference calculation 
Figure 4

NEUTRON ENERGY SPECTRUM OF SOURCE HP-15-2

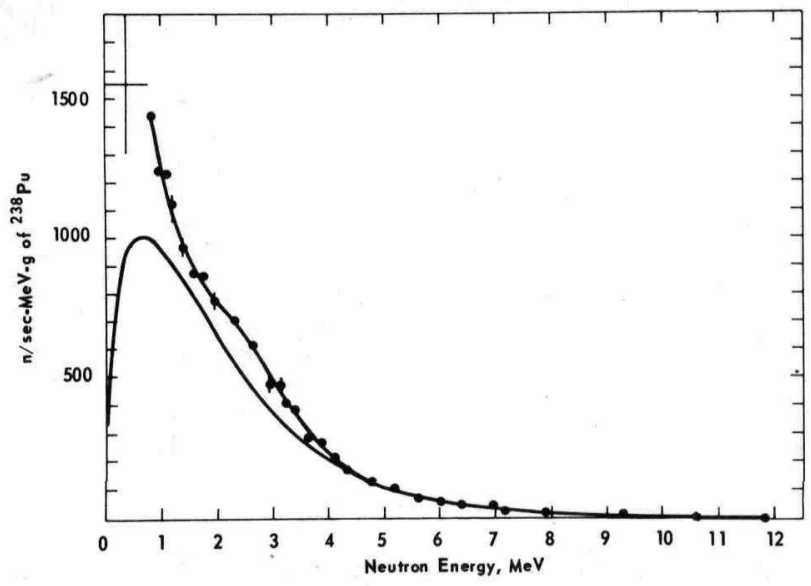

Figure 5

NEUTRON ENERGY SPECTRUM OF A $238 \mathrm{Pu}^{18}{ }^{18} \mathrm{O}(\alpha, \mathrm{n})$ SOURCE

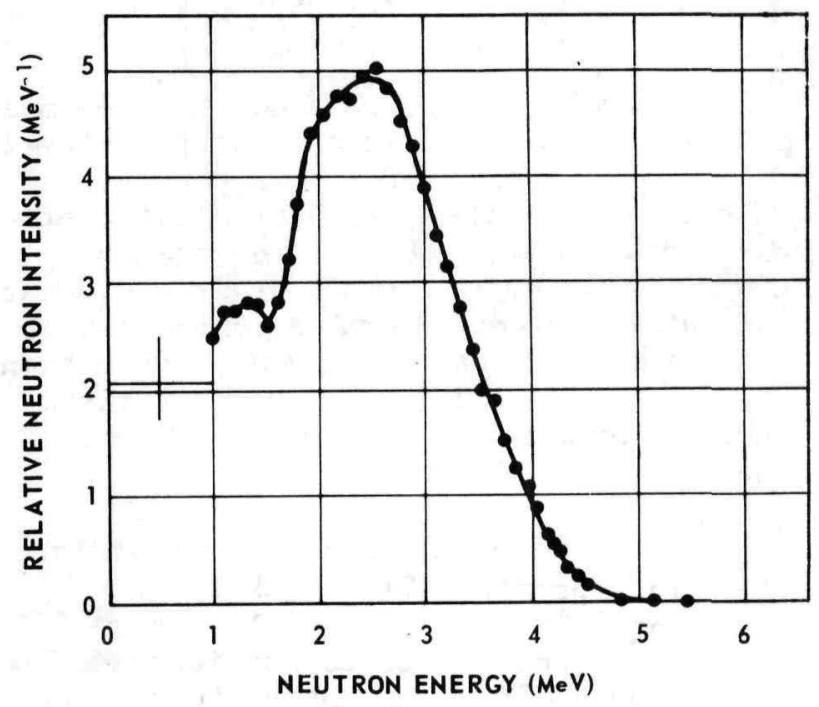

using the stilbene data and a long counter mea surement. In this spectrum, we see a broad maximum around $2.5 \mathrm{MeV}$ due to the $(\alpha, n)$ reactions with ${ }^{17} 0$ and ${ }^{18} 0$. The se $(\alpha, n)$ reactions yield about $1.4 \times 10^{4}$ $\mathrm{n} / \mathrm{sec} / \mathrm{gram}$ of ${ }^{23} \mathrm{Pu}$ in a $\mathrm{PuO}_{2}$ source with oxygen of natural isotopic abundance and give a maximum neutron energy of about $4.5 \mathrm{MeV}$. The average neutron energy from this source is $2.1 \mathrm{MeV}$.

A similar spectrum only of a $\mathrm{PuF}_{4}$ source is shown in Figure 6 . The maximum energy the neutrons from the ${ }^{19} \mathrm{~F}(\alpha, n)^{23} \mathrm{Na}$ can have, using a $5.5 \mathrm{MeV}$ alpha particle, is $3.2 \mathrm{MeV}$. This $(\alpha, n)$ reaction produces the peak at about $1.25 \mathrm{MeV}$. The average neutron energy for this source is $1.2 \mathrm{MeV}$, and the specific yield is $2.8 \times 10^{8} \mathrm{n} / \mathrm{sec} /$ gram of ${ }^{238} \mathrm{Pu}$.

Figure 6

NEUTRON ENERGY SPECTRUM

OF A ${ }^{238} \mathrm{Pu}_{\mathrm{u}}{ }^{19} \mathrm{~F}(\alpha, \mathrm{n})$ SOURCE

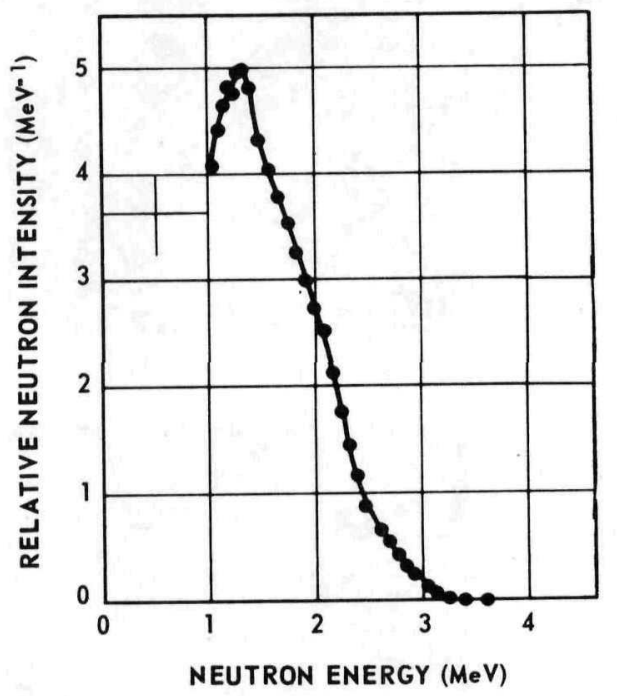

In Figure 7 we can see the effect of the neutrons due to neutron induced fission of the plutonium. The lower curve is a log plot of the data for the 15-watt metal source that was shown in Figure 4 as a linear plot. The upper curve is the neutron spectrum of a 1482 watt SNAP-27 source. Because the SNAP-27 was a natural oxygen $\mathrm{PuO}_{2}$ source, there is a broad maximum around $2.5 \mathrm{MeV}$ from the $O(\alpha, n)$ reactions. Since both of these spectra are plotted as specific yield per $\mathrm{MeV}$, the spontaneous fission spectrum for the metal source also represents the spontaneous fission curve for the SNAP-27 source. At neutron energies greater than $5 \mathrm{MeV}$, the neutron induced fission spectrum is represented by the difference between the two curves. For this SNAP-27 source, the neutron yield from induced fission was $\sim 3.7$ $\times 10^{3} \mathrm{n} / \mathrm{sec} / \mathrm{gram}$ of ${ }^{338} \mathrm{Pu}$. This gave a neutron multiplication in this source of about $20 \%$. The tota 1 specific yield for this source was $2.2 \times 10^{4} \mathrm{n} / \mathrm{sec} / \mathrm{gram}$ of ${ }^{23} \mathrm{Pu}$, and the average neutron energy was $1.9 \mathrm{MeV}$. 
Figure 7

ENERGY SPECTRA OF TWO ${ }^{238} \mathrm{PU}$ POWER SOURCES

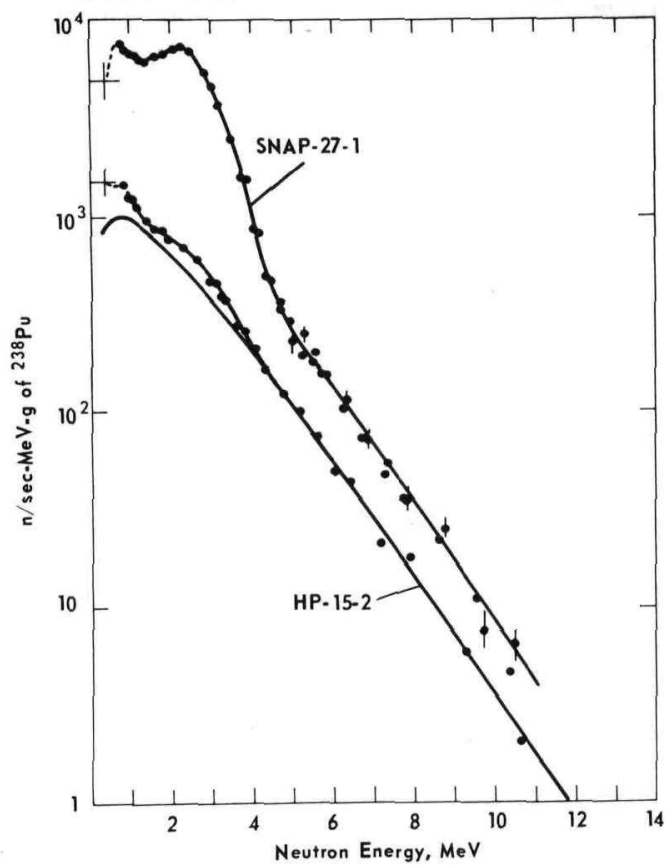

Shown in Figure 8 is the neutron spectrum of the 647-watt, PMC fueled, Pioneer capsule PF-2. The dashed line represents the spontaneous fission curve, the solid line is the sum of the spontaneous fission and induced fission curves, and the data points represent the measured neutron spectrum. The rise in the spectrum below 5 $\mathrm{MeV}$ is due to the presence of ${ }^{17} \mathrm{O}$ and ${ }^{18} \mathrm{O}$ which remained after the ${ }^{16} 0$ exchange process and to fluorine that was introduced into the fuel during the molybdenum coating process. This source had a specific yield of $3.73 \times 10^{4} \mathrm{n} / \mathrm{sec} / \mathrm{gram}$ of ${ }^{238} \mathrm{Pu}$. It is estimated from the spectral measurements that approximately $7 \%$ of these neutrons were due to spontaneous fission of the ${ }^{\text {3з } 8} \mathrm{Pu}, 7 \%$ to $O(\alpha, n)$ reactions, $23 \%$ to induced fission, and $63 \%$ to the ${ }^{19} \mathrm{~F}(\alpha, \mathrm{n})$ ${ }^{22} \mathrm{Na}$ reaction. Neutron measurements on individual PMC discs that were stacked together to make a Pioneer capsule and on the finished capsule show an increase due to multiplication of $26 \%$. The average neutron energy for this source was $1.3 \mathrm{MeV}$.

Table I contains a summary of the neutron data. From this table, we can see how prolific the oxygen and especially the fluorine are for producing neutrons. We can also see the effects of these two elements on the average energy and the dose conversion factors.

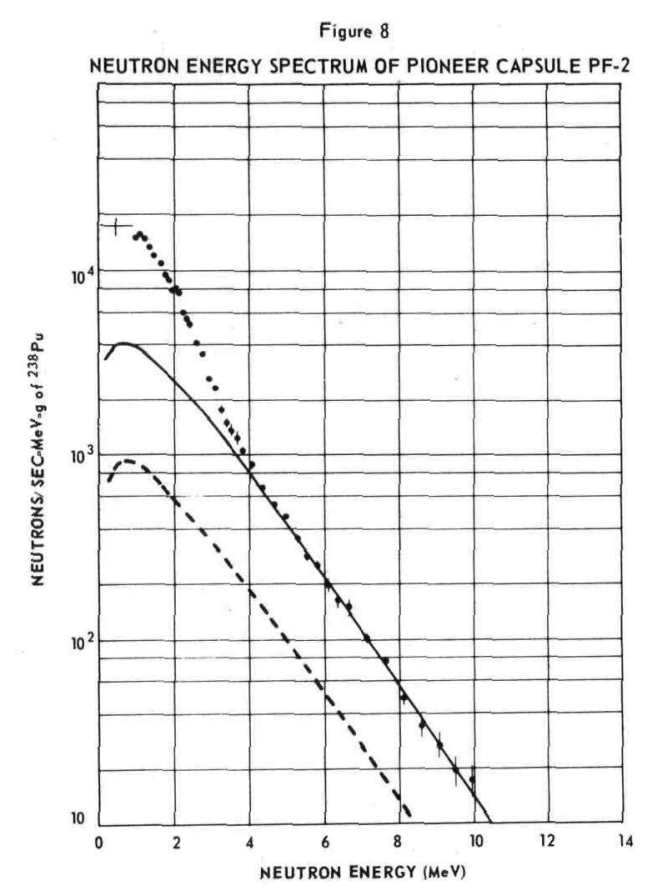

In summary, it is evident that the main problem, as far as lowering neutron levels in PMC fue1, is the fluorine content. Most likely, future PMC fuel will be produced using $\mathrm{MoCl}_{5}$ for the molybdenum coating rather than $\mathrm{MoF}_{6}$. This would keep al1 but trace amounts of fluorine out of the fuel. The small neutron contribution from ${ }^{17} \mathrm{O}$ and ${ }^{18} \mathrm{O}$ is being still further reduced through improved ${ }^{16} 0$ exchange methods.

For the gamma radiation, the fluorine is again a problem along with the ingrowth of ${ }^{236} \mathrm{Pu}$ daughters. It may be possible in the future to obtain fuel with a lower ${ }^{238} \mathrm{Pu}$ content or to age the fuel to allow some of the ${ }^{236} \mathrm{Pu}$ to decay before performing chemical separation.

Table 1

SUMMARY OF NEUTRON DATA

\begin{tabular}{|c|c|c|c|c|}
\hline \multirow[b]{2}{*}{ SOURCE } & \multirow{2}{*}{$\begin{array}{l}\text { SPECIFIC YIELD } \\
\mathrm{n} / \mathrm{sec} / \mathrm{g}{ }^{238} \mathrm{Pu}\end{array}$} & \multirow{2}{*}{$\begin{array}{l}\text { AVERAGE NEUTRON } \\
\text { ENERGY } \\
\end{array}$} & \multicolumn{2}{|c|}{$\begin{array}{l}\text { CONVERSION FACTORS FROM } \\
\text { NEUTRON FLUENCE TO }\end{array}$} \\
\hline & & & DOSE EQUIYALENT & ABSORBED DOSE \\
\hline Fission" & $2.6 \times 10^{3}$ & $2.0 \mathrm{MeV}$ & $3.3 \times 10^{-8} \mathrm{Rem} / \mathrm{n} / \mathrm{cm}^{2}$ & $3.8 \times 10^{-9} \mathrm{Rod} / \mathrm{n} / \mathrm{cm}^{2}$ \\
\hline${ }^{238} \mathrm{PuO}_{2}$ & $1.8 \times 10^{4}$ & 2.1 & 3,4 & 4.0 \\
\hline${ }^{238} \mathrm{PuF}_{4}$ & $2.8 \times 10^{6}$ & 1.2 & 3.1 & 3.3 \\
\hline SNAP-27 & $2.2 \times 10^{4}$ & 1.9 & 3.3 & 3.8 \\
\hline PF-2 & $3.7 \times 10^{4}$ & 1.3 & 3.1 & 3.4 \\
\hline
\end{tabular}

*Caiculated 